\title{
Analysis of a Methanol Decomposition Process by a Nonthermal Plasma Flow*
}

\author{
Takehiko SATO**, Makoto KAMBE*** and Hideya NISHIYAMA**
}

\begin{abstract}
In the present study, experimental and numerical analyses were adopted to clarify key reactive species for methanol decomposition processes using a nonthermal plasma flow. The nonthermal plasma flow was generated by a dielectric barrier discharge (DBD) as a radical production source. The experimental methods were as follows. Working gas was air of 1 $10 \mathrm{Sl} / \mathrm{min}$. The peak-to-peak applied voltage was $16-20 \mathrm{kV}$ with sine wave of $1 \mathrm{~Hz}-7 \mathrm{kHz}$. The characteristics of gas velocity, gas temperature, ozone concentration and methanol decomposition efficiency were measured. Those characteristics were also numerically analyzed using conservation equations of mass, chemical component, momentum and energy, and state of equation. The simulation model takes into account reactive species, which have chemical reaction with the methanol. The detailed reaction mechanism used in this model consists of 108 elementary reactions and 41 chemical species. Inlet conditions are partially given by experimental results. Finally, effects of reactive species such as $\mathrm{O}, \mathrm{OH}, \mathrm{H}, \mathrm{NO}$, etc. on methanol decomposition characteristics are numerically analyzed. The results obtained in this study are summarized as follows. (1) Existence of excited atoms of $\mathrm{O}, \mathrm{N}$ and excited molecular of $\mathrm{OH}, \mathrm{N}_{2}\left(\mathrm{~B}^{3} \Pi_{\mathrm{g}}\right), \mathrm{N}_{2}\left(\mathrm{~A}^{3} \Sigma_{u}^{+}\right)$, $\mathrm{NO}$ are implied in the discharge region. (2) The methanol below $50 \mathrm{ppm}$ is decomposed completely by using DBD at discharge conditions as $V=16 \mathrm{kVpp}$ and $f=100 \mathrm{~Hz}$. (3) The reactive species are most important factor to decompose methanol, as the full decomposition is obtained under all injection positions. (4) In numerical analysis, it is clarified that $\mathrm{OH}$ is the important radical to decompose the methanol.
\end{abstract}

Key Words: Plasma, Chemical Reaction, Non-Equilibrium, Methanol Decomposition, Radical, Experimental Analysis, Numerical Analysis

\section{Introduction}

Air pollution by flue gas, exhaust gas and volatile organic compounds (VOCs) has been caused acid rain, global warming and indoor pollutants ${ }^{(1)}$. VOCs emitted from new construction material, wall paint and wallpaper and carpet adhesives are regarded as one of causes of sick building and sick house syndromes, which has become a serious social problem ${ }^{(2)}$. Therefore, development of a decomposition method for VOCs has been strongly expected in order to improve indoor environment.

Corona discharge, dielectric barrier discharge (DBD)

* Received 24th January, 2005 (No. 05-4005)

** Institute of Fluid Science, Tohoku University, 2-1-1 Katahira, Aoba-ku, Sendai 980-8577, Japan.

E-mail: sato@ifs.tohoku.ac.jp

*** Graduate School of Engineering, Tohoku University (Presently, IBM Japan, Ltd.), 2-1-1 Katahira, Aoba-ku, Sendai 980-8577, Japan and surface discharge are known as production methods of the nonthermal plasma. Nonthermal plasma generated by high voltage discharge at atmospheric pressure has been recently utilized for environmental applications such as ozone generation for sterilization, fossil fuel conversion and decomposition of VOCs, NOx and SOx ${ }^{(3)-(10)}$. Deodorization system and air cleaner for indoor environment have been already commercialized ${ }^{(11)-(15)}$. Especially, decomposition of low concentration VOCs using nonthermal plasma flow has been paid attention as a mean of suppressing such syndrome, because it provides high chemical reactivity and a proper decomposition process even for low concentration VOCs. It has also advantages in reducing the energy input required removing the VOCs.

However, the plasma decomposition systems have not been commercialized yet so much because unknown processes are occurred in its complex chemical reactions, although its discharge processes ${ }^{(15)-(18)}$ and the gas flow effect on the breakdown voltage ${ }^{(19)}$ have been investigated. 
Therefore, the methanol, which provides enough chemical reactions among reactive species, is adopted as one of VOCs in the present study.

The objective of the present study is to clarify the methanol decomposition characteristics and processes using both experimental and numerical methods ${ }^{(20)}$. This method is very effective to clarify key chemical factors for the methanol decomposition. Because the reactive species and by-products generated in the reactive flow field include not only nitrogen oxide but also carbon oxide which means very complex. We focused on the methanol decomposition efficiency which can be measured experimentally and effects of reactive species such as $\mathrm{OH}$ and $\mathrm{O}$ on the decomposition efficiency which can be analyzed numerically.

\section{Nomenclature}

$c:$ Mole concentration $\left(\mathrm{mol} / \mathrm{m}^{3}\right)$

$d$ : Electrodes gap $(\mathrm{mm})$

$D:$ Diffusion coefficient $\left(\mathrm{m}^{2} / \mathrm{s}\right)$

$e:$ Internal energy $(\mathrm{J} / \mathrm{kg})$

$f$ : Frequency of applied voltage $(\mathrm{Hz})$

$h:$ Specific enthalpy $(\mathrm{J} / \mathrm{kg})$

$I$ : Discharge current (mA)

$P_{0}:$ Ambient pressure $(\mathrm{Pa})$

$Q:$ Gas flow rate $(\mathrm{S} l / \mathrm{min})$

$r$ : Radial coordinate $(\mathrm{mm})$

$S_{c}$ : Heat source of chemical reaction $\left(\mathrm{W} / \mathrm{m}^{3}\right)$

$T$ : Gas temperature (K)

$T_{0}$ : Ambient temperature (K)

$\boldsymbol{u}:$ Gas velocity vector $(\mathrm{m} / \mathrm{s})$

$u:$ Axial gas velocity $(\mathrm{m} / \mathrm{s})$

$v:$ Radial gas velocity $(\mathrm{m} / \mathrm{s})$

$V:$ Applied voltage $(\mathrm{kV})$

$x$ : Axial coordinate $(\mathrm{mm})$

$X$ : Mole fraction

$Y$ : Mass fraction

$W:$ Atomic weight

Greek symbols

$\phi:$ Diameter of reactor $(\mathrm{mm})$

$\Phi_{D}:$ Viscous dissipation $\left(\mathrm{W} / \mathrm{m}^{3}\right)$

$\lambda$ : Thermal conductivity $(\mathrm{W} /(\mathrm{m} \cdot \mathrm{K}))$

$\mu: \operatorname{Viscosity~}(\mathrm{kg} /(\mathrm{m} \cdot \mathrm{s}))$

$\rho:$ Density $\left(\mathrm{kg} / \mathrm{m}^{3}\right)$

$\omega$ : Rate of change of mass density $\left(\mathrm{kg} /\left(\mathrm{m}^{3} \cdot \mathrm{s}\right)\right)$

$\omega^{\prime}$ : Rate of change of mole density $\left(\mathrm{mol} /\left(\mathrm{m}^{3} \cdot \mathrm{s}\right)\right)$

Subscriptions

$i: i$ th chemical species

$k: k$ th chemical reaction

\section{Experimental Analysis}

\subsection{Experimental methods}

Figure 1 shows a schematic of an experimental apparatus. It consists mainly of a function generator (TOA

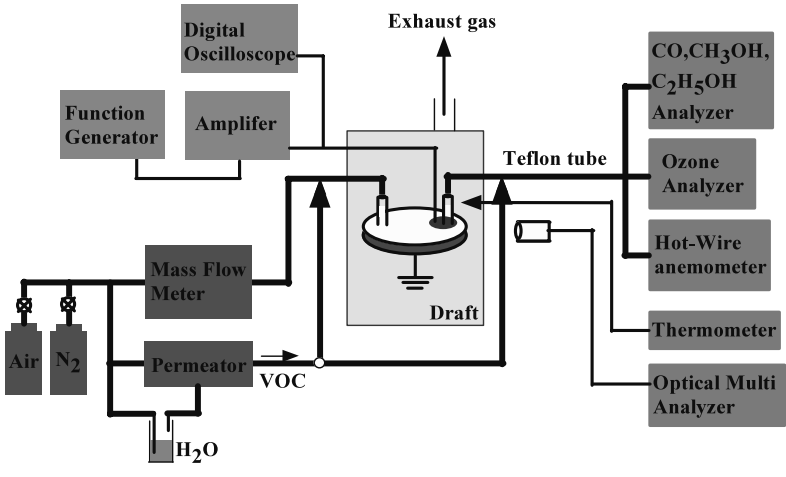

Fig. 1 Schematic of experimental apparatus

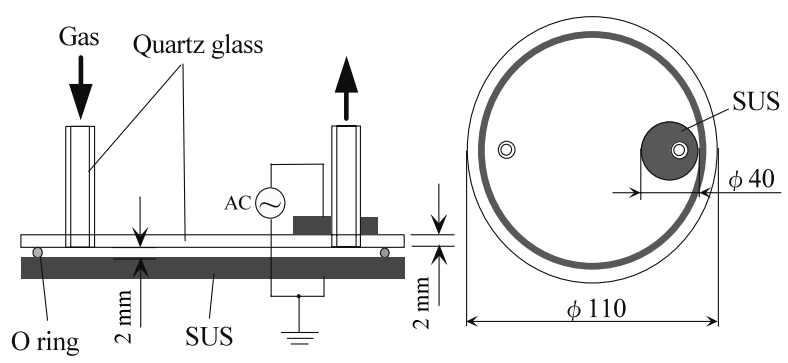

Fig. 2 Detail configuration of DBD reactor

Electronics Inc., FS-2201), an amplifier (NF Corporation, HVA4321), DBD reactor, a gas supply system and a measurement system. In this study, the DBD was adopted as a radical production source, which is one of the typical nonthermal plasma at atmospheric pressure. The DBD generates plasma between two flat-plate electrodes of which upper one is covered with quartz glass, when high voltage is applied on the electrodes. The gap length between electrodes is $4 \mathrm{~mm}$ at atmospheric pressure. Operating gas is dry air which is injected at a rate of $1-10 \mathrm{Sl} / \mathrm{min}$. Here, $\mathrm{S} / \mathrm{min}$ denotes liters/minute at the standard condition $\left(0^{\circ} \mathrm{C}\right.$ and $\left.1 \mathrm{~atm}\right)$. Applied voltage of $16-20 \mathrm{kVpp}$ is positive or negative with a sine wave of $1-7 \mathrm{kHz}$. The gas velocity, gas temperature, ozone and VOCs concentrations are respectively measured by a hot-wire anemometer (KANOMAX JAPAN Inc., Model 1008, 1010, 1013), an E-type thermocouple, an ultraviolet lay absorption method sensor (SEKIELECTRONIC Co., Ltd., SOZ-3500) and an electrochemical sensor (Dräger, Multiwarn). The discharge voltage and current can be monitored by an oscilloscope of $500 \mathrm{MS} / \mathrm{s}$ (IWATSU TEST INSTRUMENTS Corporation, DS-8814). Spectrum analysis is performed by an intensified optical multi-channel analyzer (Otsuka Electronics Co., Ltd., MCPD-7000) for 330-1100 nm and a monochrometer (Koken Kogyo Co., Ltd., SG-110) for $200-700 \mathrm{~nm}$. The resolutions of these spectrum analyses are $0.5 \mathrm{~nm}$ for wavelength.

Figure 2 shows the detail configuration of the DBD. The electrode of $40 \mathrm{~mm}$ in diameter is set around the outlet tube to reduce the electrode area and to pass all gas 
through the discharge region. The gap of the flow channel between quartz glass and the ground electrode is $2 \mathrm{~mm}$.

The methanol gas, which is regarded as VOC gas, is injected into 3 positions as shown in Fig. 3. The first position (A) is upstream of the DBD reactor to decompose methanol gas directly in the discharge region. The methanol could be reacted with high reactive species which have very short lifetime. The second position (B) is set at $100 \mathrm{~mm}$ downstream of the DBD reactor. The residence time at $4 \mathrm{Sl} / \mathrm{min}$ from the discharge region to the injection position is $10^{-2}$ seconds order which equals to the lifetime of metastable atoms. To clarify the effect of the longer lifetime of reactive species on the methanol decomposition, the third position (C) is set at $9 \mathrm{~m}$ downstream of the DBD reactor. The residence time at $4 \mathrm{Sl} / \mathrm{min}$ is 1 second order which is enough longer than the lifetime of metastable atoms. There may be unknown reactive species which has longer lifetime for sufficient decomposition of methanol. The methanol gas is supplied by a permeator.

\subsection{Experimental results and discussion}

2.2.1 Discharge characteristics Figure 4 shows the waveforms of discharge voltage, current and power under the air of $4 \mathrm{Sl} / \mathrm{min}$ with $16 \mathrm{kVpp}$ and $100 \mathrm{~Hz}$. Here, the instantaneous power is derived simply from the product of

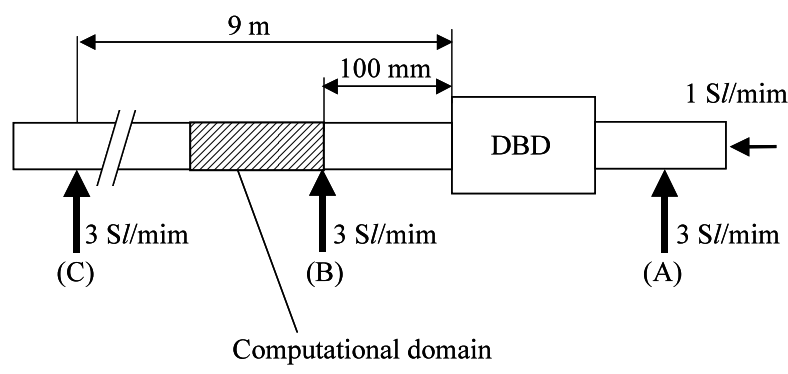

Fig. 3 Methanol gas injection positions

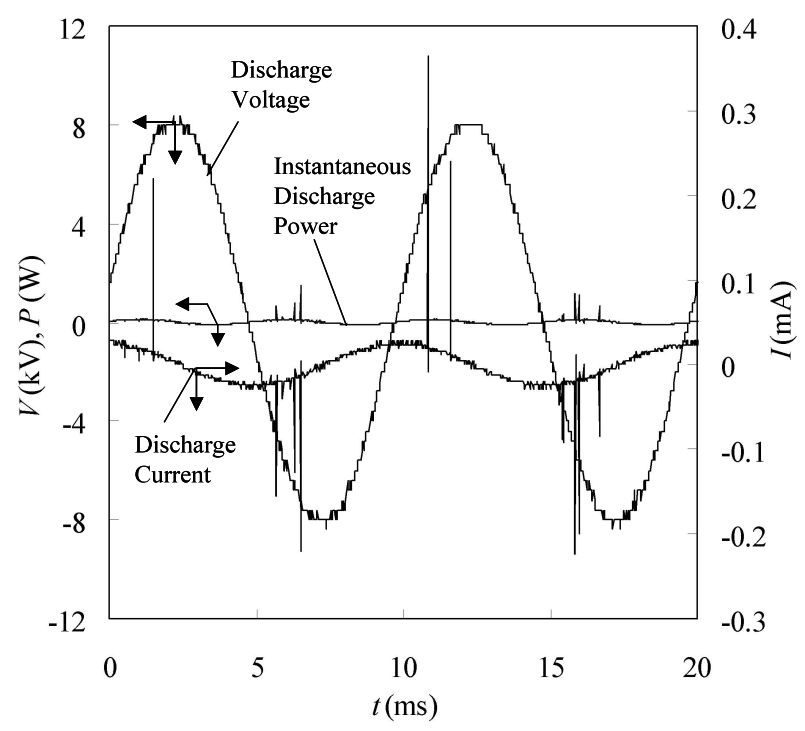

Fig. 4 Waveforms of discharge voltage, current and power discharge voltage and current, i.e. $P=V I^{(21)}$.

Figure 5 shows photographs of the discharge region under the condition of the air of $4 \mathrm{Sl} / \mathrm{min}$ with $20 \mathrm{kVpp}$, (a) $200 \mathrm{~Hz}$ and (b) $1 \mathrm{kHz}$, respectively. The brightness of the discharge is increased when the frequency is $1 \mathrm{kHz}$, because the discharge power depends on the frequency. The discharge power for one period is generally constant, as the each spark discharge time is generally within $100 \mathrm{~ns}$.

The spectral analysis results of the excited atoms and molecules in the discharge region are shown in Tables 1 and 2 , respectively. The observed emission spectra imply the existence of atoms and molecules such as $\mathrm{O}$ I, O II, $\mathrm{N}$ II, $\mathrm{N}_{2}, \mathrm{~N}_{2}^{+}, \mathrm{NO}, \mathrm{OH}^{(22),(23)}$. These reactive species are very important to the methanol decomposition process, although they generate hazardous by-products such as ozone, NOx and so on.

2.2.2 Decomposition characteristics Figure 6 shows the decomposition efficiency against the frequency under the different injection positions (A), (B) and (C) as mentioned before. When the methanol is injected into the position (A), complete decomposition is obtained at $200 \mathrm{~Hz}$. At positions of (B) and (C), complete decomposition is obtained at $700 \mathrm{~Hz}$ and $1 \mathrm{kHz}$, respectively. This result implies that lower energy is sufficient to decompose methanol at position (A). Furthermore, it is clarified that the reactive species, which are transported downstream, can react and decompose the methanol at positions of (B) and (C).

Figure 7 shows the emission intensity of the $\mathrm{OH}$ radical at $311.5 \mathrm{~nm}$ against the frequency. To change the $\mathrm{OH}$ radical concentration, water vapor humidity in the operat-

(a)

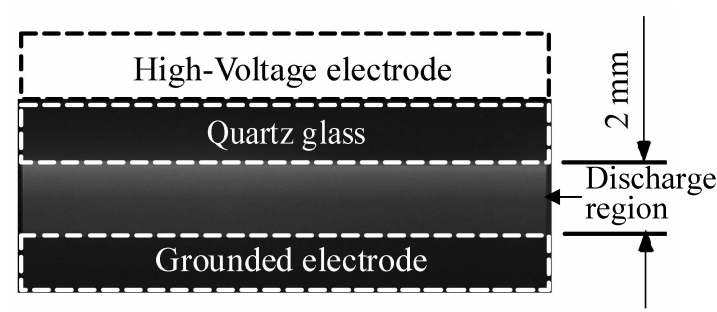

(b)

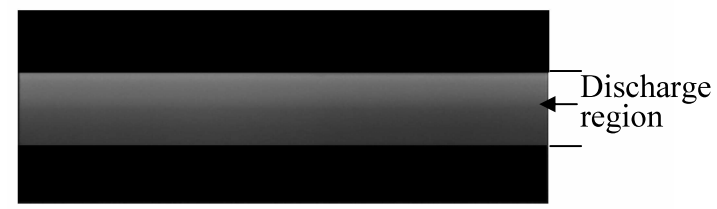

Fig. 5 Photographs of DBD region of $200 \mathrm{~Hz}$ (a) and $1 \mathrm{kHz}$ (b)

Table 1 Bright-line spectra of atoms of DBD

\begin{tabular}{|c|l|c|}
\hline Species & Wavelength $(\mathrm{nm})$ & Terms \\
\hline O I & 777 & ${ }^{5} \mathrm{~S}^{\circ}-{ }^{5} \mathrm{P}$ \\
\hline \multirow{3}{*}{ O I } & 313.47 & ${ }^{4} \mathrm{D}^{\circ}-{ }^{4} \mathrm{P}$ \\
\cline { 2 - 3 } & 352.55 & ${ }^{4} \mathrm{P}-{ }^{4} \mathrm{D}^{\circ}$ \\
\cline { 2 - 3 } & 374.94 & ${ }^{4} \mathrm{P}-{ }^{4} \mathrm{~S}^{\circ}$ \\
\hline \multirow{2}{*}{$\mathrm{N} I$} & 399.5 & ${ }^{1} \mathrm{P}^{\circ}-{ }^{1} \mathrm{D}$ \\
\hline
\end{tabular}


Table 2 Bright-line spectra of molecules of DBD

\begin{tabular}{|c|c|c|}
\hline Species & Wavelength (nm) & System \\
\hline \multirow{4}{*}{$\mathrm{N}_{2}$} & $\begin{array}{l}315.93,337.13,357.69,375.54 \\
380.49,399.84,405.94\end{array}$ & Second positive \\
\hline & 750.39 & First positive \\
\hline & 778 & Infra - red afterglow \\
\hline & 417.7 & Goldstein - Kaplan bands \\
\hline $\mathrm{N}_{2}^{+}$ & 391.4 & First negative \\
\hline \multirow{2}{*}{$\mathrm{NO}$} & $338.64,358.35,380.09$ & Bsystem \\
\hline & 861.98 & Infra-red quartet \\
\hline $\mathrm{OH}$ & $308.9,312.17$ & $3064 \mathrm{~A}$ \\
\hline
\end{tabular}

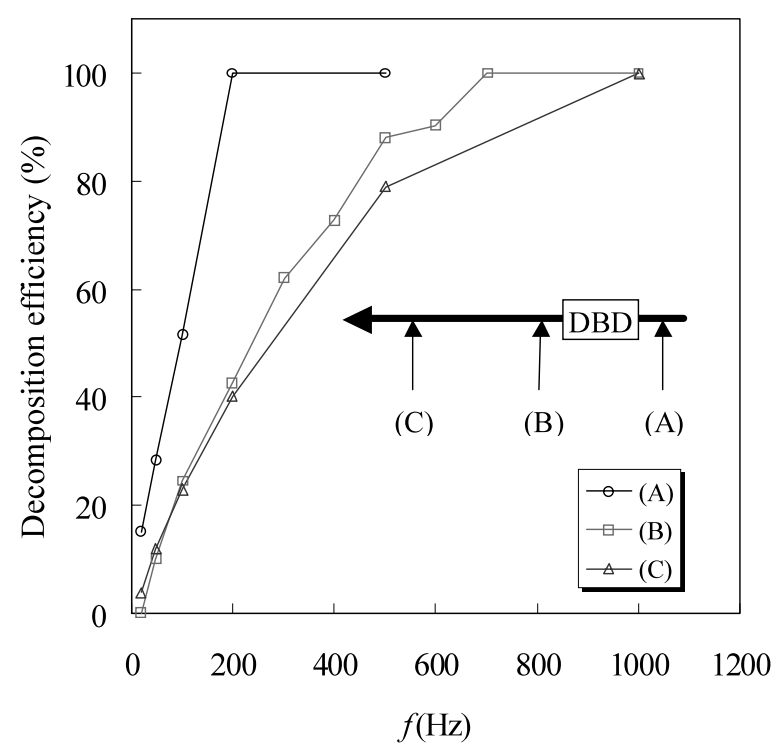

Fig. 6 Methanol decomposition efficiency against frequency under different injection locations

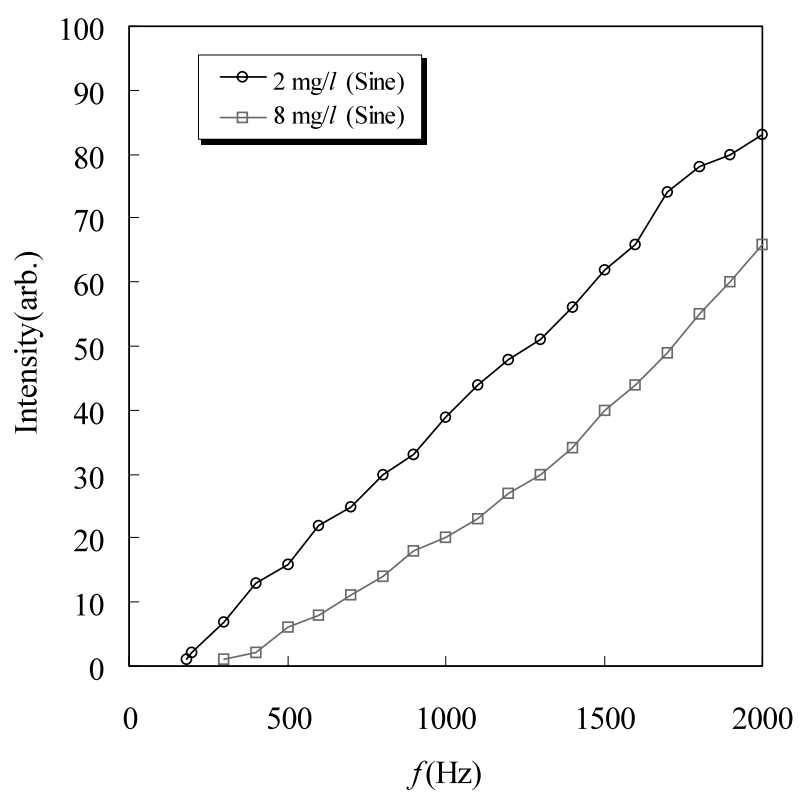

Fig. 7 Emission intensity of $\mathrm{OH}$ radical at $311.5 \mathrm{~nm}$ against the frequency

ing gas is given at $2 \mathrm{mg} / \mathrm{l}$ and $8 \mathrm{mg} / \mathrm{l}$ using water bubbling, because we focused on $\mathrm{OH}$ radical as a key chemical factor of the decomposition process. The emission intensity

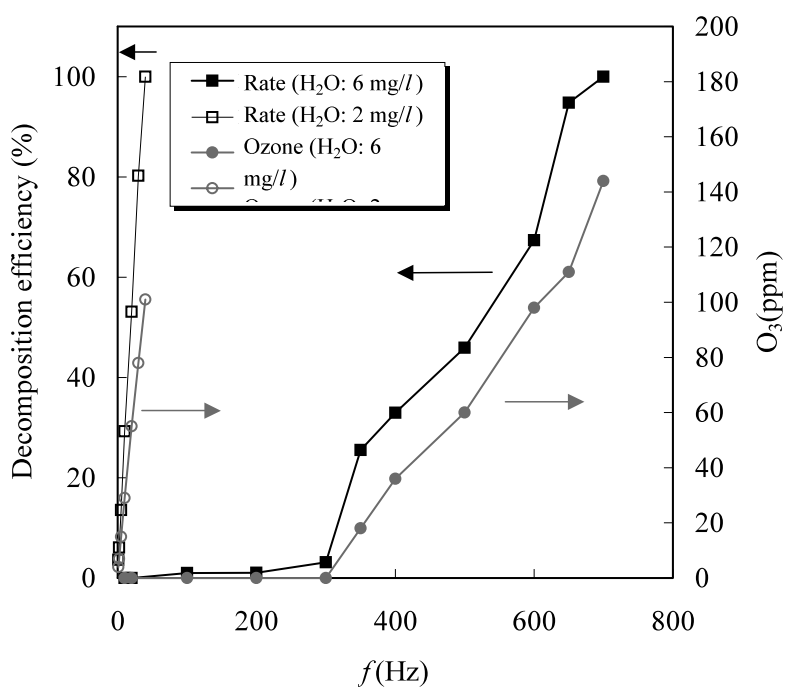

Fig. 8 Methanol decomposition efficiency and ozone concentration against frequency under different water vapor humidity

from the $\mathrm{OH}$ radical is decreased with increase in the humidity, because the discharge energy is consumed to dissociate $\mathrm{H}_{2} \mathrm{O}$. Especially, when the frequency is less than $300 \mathrm{~Hz}$, the intensity is not observed at $8 \mathrm{mg} / \mathrm{l}$.

Figure 8 shows the methanol decomposition efficiency and ozone concentration against the frequency under the different water vapor humidities at $2 \mathrm{mg} / l$ and $6 \mathrm{mg} / \mathrm{l}$. The complete decomposition is obtained at $50 \mathrm{~Hz}$ in the case of $2 \mathrm{mg} / l$, although it is obtained at $700 \mathrm{~Hz}$ in the case of $6 \mathrm{mg} / \mathrm{l}$. This result might be caused by the decrease with the $\mathrm{OH}$ radical concentration. On the other hand, the ozone concentration also shows the same tendency as the decomposition efficiency. However, there is not direct chemical equation between methanol and ozone in the database ${ }^{(24),(25)}$, although the relationship between them is obvious.

\section{Numerical Analysis}

\subsection{Numerical methods}

3.1.1 Assumptions A numerical model is based on the following assumptions: (1) electrons and ions are not considered in the reactive flow, (2) the flow is continuous, incompressible and laminar, (3) the flow, temperature and concentration fields are two-dimensionally axisymmetric, (4) gravity is negligible, (5) radiation loss and absorption are not considered ${ }^{(16)}$, and (6) the direct reaction between methanol and ozone is not considered.

\subsubsection{Governing equations Under the above-} mentioned assumptions, the governing equations are presented as follows ${ }^{(14)}$ :

Continuity equation:

$$
\nabla \cdot \boldsymbol{u}=0
$$

Momentum equation:

$$
\rho(\boldsymbol{u} \cdot \nabla) \boldsymbol{u}=-\nabla p+\mu \nabla^{2} \boldsymbol{u}
$$


Energy equation:

$$
\rho \nabla \cdot(h \boldsymbol{u})=\lambda \nabla^{2} T+\Phi_{D}+S_{C}
$$

State of equation:

$$
p=\rho R T
$$

Transport equation for chemical species, $i$ :

$$
\rho \nabla \cdot\left(Y_{i} \boldsymbol{u}\right)=\nabla \cdot \boldsymbol{J}_{i}+\omega_{i}
$$

Here, $\boldsymbol{J}_{i}$ and $\omega_{i}$ are defined as follows:

$$
\begin{aligned}
& \boldsymbol{J}_{i}=-\rho D_{i} \nabla Y_{i} \\
& \omega_{i}=W_{i} \sum_{k=1}^{K} k_{k}\left(v_{i, j}^{\prime \prime}-v_{i, j}^{\prime}\right) \prod_{j=1}^{N} c_{j}^{v_{i, j}^{\prime}}
\end{aligned}
$$

Here, the $k_{k}$ is reaction rate defined as $k_{k}=$ $A_{k} T^{n} \exp \left(-E_{k} / R T\right)$. The detailed reaction mechanism used in this model consists of 108 elementary reactions and 41 chemical species. Reaction flow analysis is performed in order to identify the specific reaction paths and the rate-limiting reactions for typical operating conditions of the DBD reactor. Inlet conditions of gas velocity, gas temperature are given by experimental results. The ozone concentration of $100 \mathrm{ppmv}$ is given

\begin{tabular}{|c|c|c|}
\hline No. & Chemical reaction & Rate coefficient $\left(\mathrm{cm}^{3}\right.$ molecule $\left.{ }^{-1} \mathrm{~s}^{-1}\right)$ \\
\hline 5 & $\mathrm{H}+\mathrm{HO}_{2} \rightarrow 2 \mathrm{OH}$ & $7.2 \times 10^{-11}$ \\
\hline 9 & $\mathrm{O}+\mathrm{HO}_{2} \rightarrow \mathrm{OH}+\mathrm{O}_{2}$ & $2.7 \times 10^{-11} \exp (224 / \mathrm{T})$ \\
\hline 11 & $\mathrm{OH}+\mathrm{H}_{2} \rightarrow \mathrm{H}_{2} \mathrm{O}+\mathrm{H}$ & $7.7 \times 10^{-12} \exp (-2100 / \mathrm{T})$ \\
\hline 12 & $2 \mathrm{OH} \rightarrow \mathrm{H}_{2} \mathrm{O}+\mathrm{O}$ & $6.2 \times 10^{-14}(\mathrm{~T} / 298)^{2.6} \exp (945 / \mathrm{T})$ \\
\hline 20 & $\mathrm{O}+\mathrm{NO}+\mathrm{N}_{2} \rightarrow \mathrm{NO}_{2}+\mathrm{N}_{2}$ & $1.0 \times 10^{-31}(\mathrm{~T} / 300)^{-1.6}\left[\mathrm{~N}_{2}\right]$ \\
\hline 35 & $\mathrm{HO}_{2}+\mathrm{NO}_{3} \rightarrow \mathrm{O}_{2}+\mathrm{HNO}_{3}$ & $4.0 \times 10^{-12}$ \\
\hline 46 & $2 \mathrm{NO}+\mathrm{O}_{2} \rightarrow 2 \mathrm{NO}_{2}$ & $3.3 \times 10^{-39} \exp (530 / \mathrm{T})$ \\
\hline 61 & $\mathrm{OH}+\mathrm{CO} \rightarrow \mathrm{H}+\mathrm{CO}_{2}$ & $2.08 \times 10^{-13}$ \\
\hline 62 & $\mathrm{CO}+\mathrm{O}+\mathrm{N}_{2} \rightarrow \mathrm{CO}_{2}+\mathrm{N}_{2}$ & $1.11 \times 10^{-35}\left[\mathrm{~N}_{2}\right]$ \\
\hline 67 & $\mathrm{OH}+\mathrm{CH}_{3} \mathrm{OH} \rightarrow \mathrm{H}_{2} \mathrm{O}+\mathrm{CH}_{2} \mathrm{OH}$ & $7.9 \times 10^{-13}$ \\
\hline 68 & $\mathrm{OH}+\mathrm{CH}_{3} \mathrm{OH} \rightarrow \mathrm{H}_{2} \mathrm{O}+\mathrm{CH}_{3} \mathrm{O}$ & $1.4 \times 10^{-13}$ \\
\hline 70 & $\mathrm{H}+\mathrm{CH}_{3} \mathrm{OH} \rightarrow \mathrm{H}_{2}+\mathrm{CH}_{2} \mathrm{OH}$ & $2.816 \times 10^{-17} \mathrm{~T}^{2.1} \exp (-2450 / \mathrm{T})$ \\
\hline 73 & $\mathrm{O}+\mathrm{CH}_{3} \mathrm{OH} \rightarrow \mathrm{OH}+\mathrm{CH}_{3} \mathrm{O}$ & $3.22 \times 10^{-19} \mathrm{~T}^{2.5} \exp (-1550 / \mathrm{T})$ \\
\hline 81 & $\mathrm{CH}_{2} \mathrm{OH}+\mathrm{OH} \rightarrow \mathrm{HCHO}+\mathrm{H}_{2} \mathrm{O}$ & $4.0 \times 10^{-11}$ \\
\hline 104 & $\mathrm{CH}_{3} \mathrm{O}+\mathrm{NO}_{2} \rightarrow \mathrm{HCHO}+\mathrm{HONO}$ & $9.6 \times 10^{-12} \exp (-1150 / \mathrm{T})$ \\
\hline
\end{tabular}
by using representative experimental result. The main chemical reactions are shown in the Table $3^{(24),(25)}$. The reaction pathways adopted in this study for the methanol

Table 3 Main chemical reactions decomposition is shown in Fig. 9. The methanol $\left(\mathrm{CH}_{3} \mathrm{OH}\right)$ is decomposed to $\mathrm{CH}_{2} \mathrm{OH}$ and $\mathrm{CH}_{3} \mathrm{O}$ by reactions with $\mathrm{OH}, \mathrm{O}, \mathrm{O}_{2}$ and $\mathrm{HO}_{2}$ in the first step. In the second step, the $\mathrm{CH}_{2} \mathrm{OH}$ is decomposed to $\mathrm{HCHO}, \mathrm{CO}$ and $\mathrm{CH}_{3}$ by reactions with $\mathrm{OH}, \mathrm{O}, \mathrm{H}, \mathrm{O}_{2}, \mathrm{HO}_{2}$ and $\mathrm{HCHO}$. The $\mathrm{CH}_{3} \mathrm{O}$ is converted to $\mathrm{CH}_{3} \mathrm{ONO}$ and $\mathrm{CH}_{3} \mathrm{ONO}_{2}$ by reactions with $\mathrm{NO}$ and $\mathrm{NO}_{2}$. The $\mathrm{CH}_{3}$ and the $\mathrm{HCO}$ are converted to the $\mathrm{CO}$ and finally the $\mathrm{CO}$ is converted to $\mathrm{CO}_{2}$. In these reaction pathways, a direct reaction with the ozone can not be considered due to the lack of data. However, the ozone has surely indirect contributions for these pathways by generating $\mathrm{OH}$ and $\mathrm{HO}_{2}$. Thus, effects of high reactive species such as $\mathrm{O}$ and $\mathrm{OH}$ are numerically analyzed.

3.1.3 Computational domain and boundary conditions The computational domain is a cylindrical geometry of $10 \mathrm{~mm}$ length and $2 \mathrm{~mm}$ radius. It is located downstream of the DBD reactor, which is same as position (B), as shown in Fig. 3. The methanol injection location is assumed in front of the inlet of the computational domain. The boundary conditions are given as follows:

Inlet: $u=u_{\text {exp }}, \quad v=0, T=T_{0}, \quad Y_{i}=$ given

Axis: $\frac{\partial u}{\partial r}=v=0, \quad \frac{\partial T}{\partial r}=0, \quad \frac{\partial Y_{i}}{\partial r}=0$

Wall: $u=v=0, \quad T=$ const.,$\quad \frac{\partial Y_{i}}{\partial r}=0$

Exit: $\frac{\partial u}{\partial x}=\frac{\partial v}{\partial x}=0, \quad \frac{\partial T}{\partial x}=0, \quad \frac{\partial Y_{i}}{\partial x}=0$

3.1.4 Computational conditions The $u_{\exp }$ in the inlet conditions is given experimentally by using the radial distribution of axial gas velocity as shown in Fig. 10. Table 4 shows computational conditions. Inlet temperature and ambient temperature are given by using experimental data. Compositions of the chemical species are given at the inlet of the reactor ${ }^{(26)}$. The velocity, temperature and concentration fields are simulated by using CFD-ACE+ code (CFD Research Co., Alabama, USA) which employs the SIMPLEC method ${ }^{(27),(28)}$. The units of ppmv and ppmw in the table denote volume ppm and weight ppm, respectively.

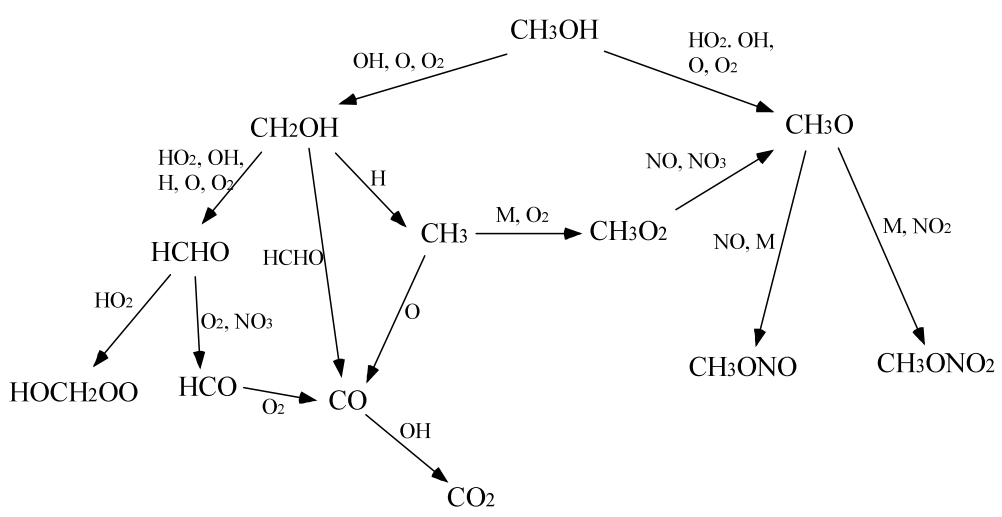

Fig. 9 Plausible reaction pathways for methanol decomposition in air 
(a)

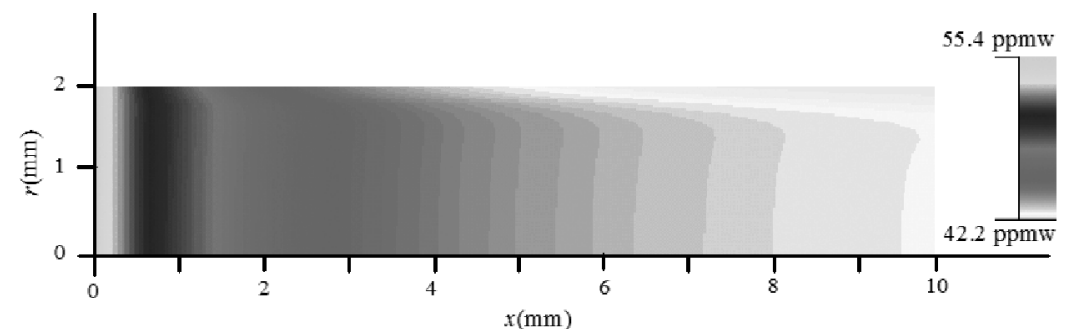

(b)

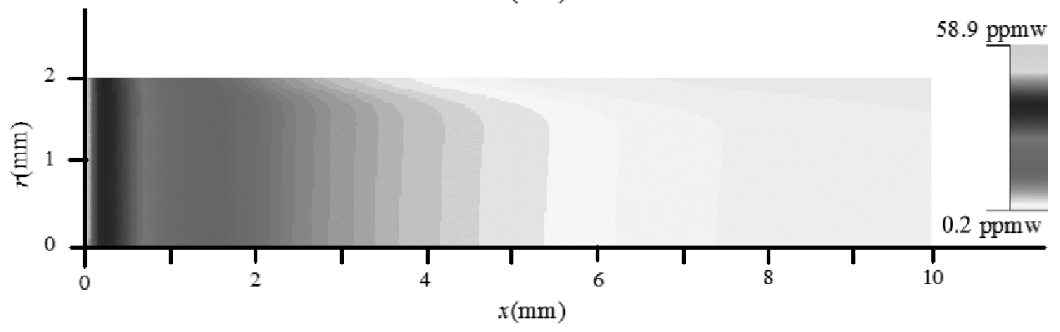

Fig. 11 Distributions of $\mathrm{CH}_{3} \mathrm{OH}$ (a) and $\mathrm{OH}$ (b) concentrations

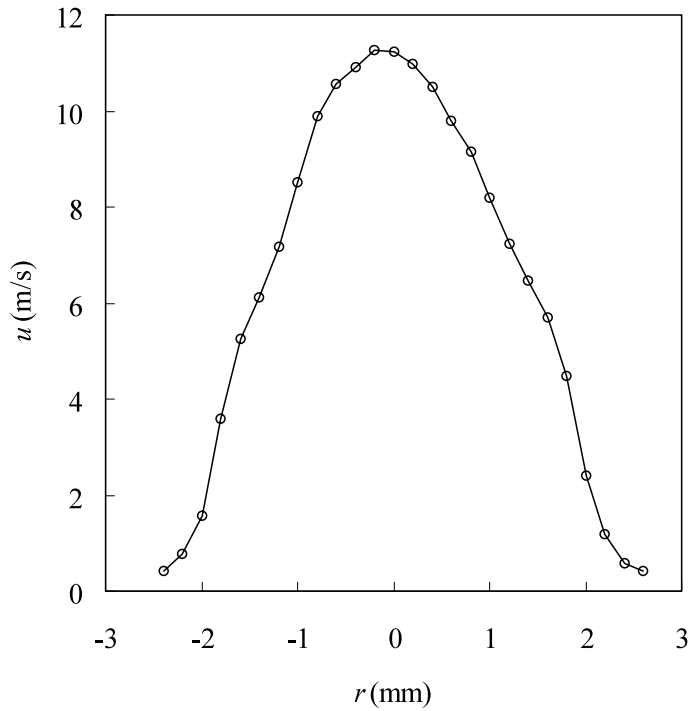

Fig. 10 Radial distribution of axial gas velocity

Table 4 Computational conditions

\begin{tabular}{|c|c|c|c|}
\hline \multicolumn{2}{|c|}{ Pressure $(\mathrm{Pa})$} & \multicolumn{2}{|c|}{$1.00 \mathrm{E}+05$} \\
\hline \multicolumn{2}{|c|}{ Ambient Temp. (K) } & \multicolumn{2}{|c|}{290} \\
\hline \multicolumn{2}{|c|}{ Inlet Temp. (K) } & \multicolumn{2}{|c|}{290} \\
\hline \multirow{9}{*}{$\begin{array}{c}\text { Chemical } \\
\text { species }\end{array}$} & $\mathrm{N}_{2}$ & 77.7 vol. $\%$ & 75.4 wt. $\%$ \\
\hline & $\mathrm{O}_{2}$ & 22.0 vol. $\%$ & 24.4 wt. $\%$ \\
\hline & $\mathrm{H}_{2} \mathrm{O}$ & 0.2 vol. $\%$ & 0.12 wt. $\%$ \\
\hline & $\mathrm{OH}$ & $100 \mathrm{ppmv}$ & $58.9 \mathrm{ppmw}$ \\
\hline & $\mathrm{O}_{3}$ & $100 \mathrm{ppmv}$ & $166 \mathrm{ppmw}$ \\
\hline & $\mathrm{CH}_{3} \mathrm{OH}$ & $50 \mathrm{ppmv}$ & $55.4 \mathrm{ppmw}$ \\
\hline & $\mathrm{O}$ & $100 \mathrm{ppmv}$ & $55.4 \mathrm{ppmw}$ \\
\hline & $\mathrm{H}$ & $10 \mathrm{ppmv}$ & $0.346 \mathrm{ppmw}$ \\
\hline & NO & $10 \mathrm{ppmv}$ & $10.4 \mathrm{ppmw}$ \\
\hline
\end{tabular}

\subsection{Numerical results and discussion}

Figure 11 shows the distributions of $\mathrm{CH}_{3} \mathrm{OH}$ (a) and $\mathrm{OH}$ (b) concentrations. The methanol concentration is de-

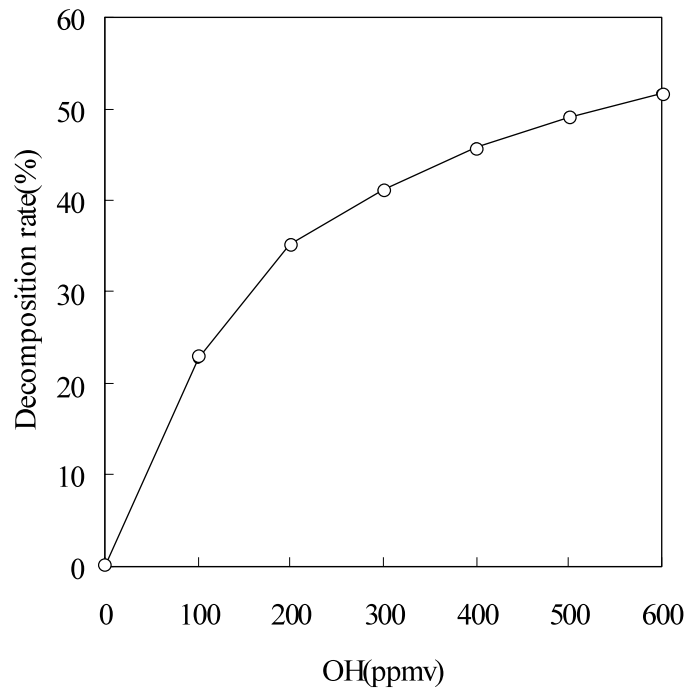

Fig. 12 Effect of $\mathrm{OH}$ radical on methanol decomposition efficiency

creased in the downstream from 55.4 ppmw to 42.8 ppmw. The $\mathrm{OH}$ concentration also shows the same tendency as the methanol one, correspondingly. These processes might be caused by the following chemical reactions:

$$
\begin{aligned}
& \mathrm{O}+\mathrm{CH}_{3} \mathrm{OH} \rightarrow \mathrm{OH}+\mathrm{CH}_{2} \mathrm{OH} \\
& \mathrm{O}+\mathrm{CH}_{3} \mathrm{OH} \rightarrow \mathrm{OH}+\mathrm{CH}_{3} \mathrm{O} \\
& \mathrm{OH}+\mathrm{CH}_{3} \mathrm{OH} \rightarrow \mathrm{H}_{2} \mathrm{O}+\mathrm{CH}_{2} \mathrm{OH} \\
& \mathrm{OH}+\mathrm{CH}_{3} \mathrm{OH} \rightarrow \mathrm{H}_{2} \mathrm{O}+\mathrm{CH}_{3} \mathrm{O}
\end{aligned}
$$

Methanol can be also decomposed by $\mathrm{O}$ radical. Figures 12 and 13 show the effect of $\mathrm{OH}$ and $\mathrm{O}$ radicals on the decomposition efficiency, respectively. When the only $\mathrm{OH}$ concentration is increased up to $600 \mathrm{ppmv}$ at inlet under keeping the constant concentration of other chemical species, the decomposition efficiency is increased up to $50 \%$. On the other hand, when the only $\mathrm{O}$ concentration is increased up to $200 \mathrm{ppmv}$, the decomposition ef- 


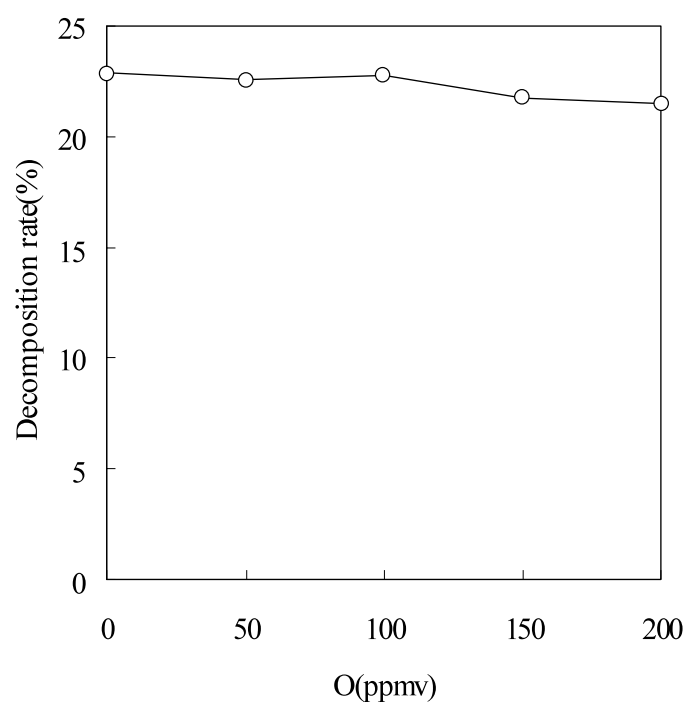

Fig. 13 Effect of O radical on methanol decomposition efficiency

ficiency shows almost constant. This result implies that the decomposition process is independent of the $\mathrm{O}$ radical. However, even if the $\mathrm{OH}$ concentration is increased at inlet, full methanol decomposition is not achieved. The unconsidered chemical reaction formula or a reaction rate coefficient, and the chemistry species should be prepared for more realistic numerical analysis.

\section{Conclusions}

The experimental and numerical analyses were conducted to clarify key reactive species for the methanol decomposition processes using a nonthermal plasma flow. This study could propose a new method for analyzing other VOC decomposition processes which are very complex flow. The results obtained in this study are summarized as follows.

1. Radicals for contributing methanol decomposition, such as excited atom of $\mathrm{O}, \mathrm{OH}, \mathrm{N}$ and excited molecular of $\mathrm{N}_{2}\left(\mathrm{~B}^{3} \Pi_{\mathrm{g}}\right), \mathrm{N}_{2}\left(\mathrm{~A}^{3} \Sigma_{u}^{+}\right)$, NO are implied to exist experimentally in the dielectric barrier discharge region.

2. When the dry air containing $2 \dot{\mathrm{mg}} / \mathrm{L}$ of water vapor is used as the carrier gas, DBD decompose the methanol completely below $50 \mathrm{ppm}$ at discharge conditions of $V=$ $16 \mathrm{kVpp}$ and $f=100 \mathrm{~Hz}$. The intensity of $\mathrm{OH}$ radiation is greater than $6 \mathrm{mg} / \mathrm{L}$ of water vapor which cause the decrease with the decomposition efficiency in this case.

3. When the rate of methanol decomposition is compared each other, the case (A) is the best, however full decomposition is obtained in the cases (B) and (C). This result implies that the unknown reactive species which has long lifetime cause to decompose methanol, experimentally. In numerical analysis, it is indicated that $\mathrm{OH}$ is important radical to decompose the methanol in the case (B) under the adopted chemical reaction data in this study.

\section{Acknowledgement}

The present study was supported by grant in aid for research encouragement from the Japan Society for Promotion of Science (No. 15760100) and by the Institute of Fluid Science, Tohoku University, Japan.

\section{References}

( 1 ) Hackam, R. and Akiyama, H., Air Pollution Control by Electrical Discharges, IEEE Trans. Dielectric and Electrical Insulation, Vol.7 (2000), pp.654-683.

( 2 ) Jones, A.P., Indoor Air Quality and Health, Atmospheric Environment, Vol.33 (1999), pp.4535-4564.

( 3 ) Oda, T., Kumada, A., Tanaka, K., Takahashi, T. and Masuda, S., Low Temperature Atmospheric Pressure Discharge Plasma Processing for Volatile Organic Compounds, J. of Electrostatics, Vol.35 (1995), pp.93101.

( 4 ) Filimonova, E.A., Kim, Y.H., Hong, S.H., Han, S.Y. and Song, Y.H., Multiparametric Investigation on NOx Removal from Diesel-Like Exhaust Gas with Hydrocarbons by Pulsed Corona Discharge, Proc. 15th Int. Symp. on Plasma Chem., VII, (2001), pp.3041-3052.

( 5 ) Li, R., Yan, K., Miao, J. and Wu, X., Heterogeneous Reactions in Non-Thermal Plasma Flue Gas Desulfurization, Chem. Eng. Sci., Vol.53 (1998), pp.15291540.

( 6 ) Yan, P., Fujiwara, M., Zhou, Y. and Ishida, M., Investigation on Luminescence and NOx Removal by Pulse Corona Discharges, J. Electrostatics, Vol.51-52 (2001), pp.266-271.

( 7 ) Kim, H.H., Prieto, G., Takashima, K., Katsura, S. and Mizuno, A., Performance Evaluation of Discharge Plasma Process for Gaseous Pollutant Removal, J. Electrostatics, Vol.55 (2002), pp.25-41.

( 8 ) Rajanikanth, B.S. and Rout, S., Studies on Nitric Oxide Removal in Simulated Gas Compositions under Plasma-Dielectric/Catalytic Discharges, Fuel Processing Technology, Vol.74 (2001), pp.177-195.

( 9 ) Hu, X., Nicholas, J., Zhang, J.J., Linjewile, T.M., Filipps, P.D. and Agarwal, P.K., The Destruction of $\mathrm{N}_{2} \mathrm{O}$ in a Pulsed Corona Discharge Reactor, Fuel, Vol.81 (2002), pp.1259-1268.

(10) Okazaki, K., Hirai, S., Nozaki, T., Ogawa, K. and Hijikata, K., Plasma Chemical Reactions at Atmospheric Pressure for High Efficiency Use of Hydrocarbon Fuels, Energy, Vol.22 (1997), pp.369-374.

(11) Masuda, S., Hosokawa, S., Tu, X.L., Tsutsumi, M., Ohtani, T., Tsukahara, T. and Matsuda, N., The Performance of an Integrated Air Purifier for Control of Aerosol, Microbial, and Odor, IEEE Trans. Ind. Appl., Vol.29 (1993), pp.774-780.

(12) Kisanuki, Y., Yoshida, M., Takashima, K., Katsura, S., Mizuno, A., Lee, S.H., Hong, Y.K. and Kang, K.O., J. Inst. Electrostat. Jpn., Vol.24 (2000), pp.153-158.

(13) Zhang, R.H., Yamamoto, T. and Bundy, D.S., Control of Ammonia and Odors in Animal Houses by a Ferroelectric Plasma Reactor, IEEE Trans. Ind. Appl., Vol.32 (1996), pp.113-117.

(14) Okubo, M., Yamamoto, T., Kuroki, T. and Fukumoto, 
H., Electric Air Cleaner Composed of Nonthermal Plasma Reactor and Electrostatic Precipitator, IEEE Trans. Ind. Appl., Vol.37 (2001), pp.1505-1511.

(15) Okubo, M., Kuroki, T., Kametaka, H. and Yamamoto, T., Odor Control Using the AC Barrier-Type Plasma Reactors, IEEE Trans. Ind. Appl., Vol.37 (2001), pp.1447-1455.

(16) Kulikovsky, A.A., The Efficiency of Radicals Production by Positive Streamer in Air: The Role of Laplacian Field, IEEE Trans. on Plasma Science, Vol.29 (2001), pp.313-317.

(17) Kim, Y.-H. and Hong, S.H., Two-Dimensional Simulation Images of Pulsed Corona Discharges in a WirePlate Reactor, IEEE Trans. Plasma Science, Vol.30 (2002), pp.168-169.

(18) Futamura, S., Zhang, A.H. and Yamamoto, T., The Dependence of Nonthermal Plasma Behavior of VOCs on Their Chemical Structures, J. of Electrostatics, Vol.42 (1997), pp.51-62.

(19) Sato, T., Nishiyama, H. and Kambe, M., Characteristics of Breakdown Boltage at a Narrow Gap in a NonThermal Plasma Flow, J. of the Korean Physical Society, Vol.42 (2003), pp.S782-S786.

(20) Sato, T., Ito, D. and Nishiyama, H., Reaction Field Analysis of a Non-Thermal Plasma Flowing in a Rectangular Reactor, Thin Solid Films, Vol.457 (2004), pp.78-83.
(21) Okubo, M., Kuroki, T., Miyairi, Y. and Yamamoto, T., Low-Temperature Soot Incineration of Diesel Particulate Filter Using Remote Nonthermal Plasma Induced by a Pulsed Barrier Discharge, IEEE Trans. Ind. Appl., Vol.40 (2004), pp.1504-1512.

(22) NIST Atomic Spectra Database, http://physics.nist.gov/cgi-bin/AtData/main_asd

(23) Pease, R.W.B. and Gaydon, A.G., The Identification of Molecular Spectra, (1963), Chapman \& Hall, London.

(24) Atkinson, R., Baulch, D.L., Cox, R.A., Crowley, J.N., Hampson, R.F., Kerr, J.A., Rossi, M.J. and Troe, J., Summary of Evaluated Kinetic and Photochemical Data for Atmospheric Chemistry, IUPAC Subcommittee on Gas Kinetic Data Evaluation for Atmospheric Chemistry, Available at http://www.iupac-kinetic.ch. cam.ac.uk/index.html

(25) Tsang, W., Chemical Kinetic Data Base for Combustion Chemistry. Part 2. Methanol, J. Phys. Chem. Ref. Data, Vol.16 (1987), pp.471-508.

(26) Eliasson, B. and Kogelschatz, U., Modeling and Applications of Silent Discharge Plasmas, IEEE Trans. Plasma Science, Vol.19 (1991), pp.309-323.

(27) CFD Research Corporation, (2001), CFD-ACEU Module Manual.

(28) CFD Research Corporation, (2001), CFD-ACEU User Manual. 